\title{
A model of determinants for continuous usage of business intelligence in Malaysian manufacturing organizations using theoretical
}

\author{
Ernie Mazuin Mohd Yusof ${ }^{1}$, Mohd Shahizan Othman ${ }^{2}$, Ahmad Rizal Mohd Yusof ${ }^{3}$, \\ Zirawani Baharum ${ }^{4}$ \\ 1,4 Instrumentation and Control Engineering Section, Malaysian Institute of Industrial Technology, \\ Universiti Kuala Lumpur, Malaysia \\ ${ }^{2}$ Centre of Information and Communication Technology, Universiti Teknologi Malaysia, Malaysia \\ ${ }^{3}$ Institute of Ethnic Studies, Universiti Kebangsaan Malaysia, Malaysia
}

\section{Article Info}

Article history:

Received Sep 15, 2019

Revised Dec 16, 2019

Accepted Dec 30, 2019

Keywords:

Business intelligence

Continuance

Determinants

Manufacturing

\begin{abstract}
Business Intelligence (BI) offered many advantages to organizations adopting the system such as improved decision making and boost organization's performance. The lack of research on the continuous usage of $\mathrm{BI}$ in manufacturing motivates the initiative in this study to have an understanding of the determinants that influenced it. The study proposed a model of individual-related determinants that lead to the continuous usage of BI in manufacturing. A model integrating Unified Theory of Acceptance and Use of Technology (UTAUT) and Information System Continuance Model (ISCM) will be developed. The model will portray 20 hypotheses and 11 determinants leading continuance usage of BI. Data will be collected through survey questionnaires instrument and validated using Structural Equation Modelling (SEM). The result is hoping to show significant relationships between the determinants towards the continuous usage of BI in manufacturing. The study can potentially be used to guide manufacturers and practitioners for considerations in implementing $\mathrm{BI}$ in the manufacturing industry.
\end{abstract}

Copyright $@ 2020$ Institute of Advanced Engineering and Science. All rights reserved.

\section{Corresponding Author:}

Ernie Mazuin Mohd Yusof,

Instrumentation and Control Engineering Section,

Malaysian Institute of Industrial Technology (MITEC),

Universiti Kuala Lumpur, Seri Alam, Johor, Malaysia.

Email: erniemazuin@unikl.edu.my

\section{INTRODUCTION}

The ability of Business Intelligence (BI) system to analyze considerable volume of data into useful information has made it a valuable technological tool for organizations [1]. The role of BI that turned the data into knowledge to facilitate users and aid the decision making process has made the system well recognized by organizations, including the manufacturing. BI usage in manufacturing has shown an uplifting trend where it has given many advantages such as providing faster fact-based decision making that improves business processes and identifying potential customers.

Many studies were conducted on BI in manufacturing but there were less studies conducted on human related factors that affect the continuous usage of it. Therefore, the objective of this study is to propose a model of determinants for continuous usage of BI in Malaysian manufacturing industry. This model integrates the dominant theories of Unified Theory of Acceptance and Usage of Technology (UTAUT) and Information System Continuance Model (ISCM). UTAUT and ISCM are robust models in the 
ground of individual-related factors that influence the continuous usage of BI. The integration will formulate 20 hypothesis and 11 factors of individual-related continuous factors.

This study contributes to knowledge whereby a more comprehensive model will be developed focusing on individual factors influencing the continuous usage of BI. Other contribution would be in the manufacturing industry where manufacturers could benefit from the research model towards the BI implementation in manufacturing organizations.

This paper is organized as follows. Section 2 describes the literature review. Section 3 synthesizes the theoretical models used as the basis for the research model. Section 4 presents the research model and the derivation of the hypothesis. Section 5 describes the methodology used to test the research model for its constructs and hypothesis, as well as the data analysis method. Section 6 discusses the expected result of the study. Finally, Section 7 presents the discussion and conclusion of the study.

\section{LITERATURE REVIEW}

Despite the predominant implementation of BI in organizations whether of multinational or international type, there were failures reported in relation with the implementation of it [2-4]. For this reason, many researches were conducted to study pertaining to the issues. Past researches that focused on Critical Success Factors (CSF) as well as key success factors on the BI implementation in organizations have been largely conducted [5-7]. Nevertheless, there were less studies conducted at the individual level, especially on the users' continuous usage of BI [8-10]. This is also in line with the study by Kumar et al., (2016) [11] as the editorial team who analyzed hundreds of journals related to Enterprise System (ES) as a whole and found out that most of the ES studies were focusing on the organizational-level rather than technical and social aspects.

Few studies were done previously concerning the users' adoption and acceptance of BI [8, 12, 13]. Those studies developed models that were originated from various underlying theoretical models whose variables were evaluated using respective measurement method. However, the developed models did not incorporate demographic characteristics such as individual and social-related factors in them to determine the acceptance of BI among the users that eventually lead to the continuance usage of it. Hou (2014) and Sönmez (2018) $[12,14]$ mentioned that there is a need for future research to consider the effects of age, gender, experience, education level and other demographic characteristics to examine whether they have direct impacts and can make a difference towards the users' behavior and subsequently towards the continuous use of BI. Furthermore, it is important to investigate on the continuous usage of BI among the users to provide concrete understanding towards the role and usage of BI, and to guide the industry to develop BI systems that can meet the users' need [15]. Thus, the determinants influencing the user's continuous usage of BI require in-depth study.

Additionally, in Malaysia, the BI adoption in organizations is still in its infancy stage. This is due to the lack of user acceptance that leads towards continuous usage the system [16-18]. The recent studies were conducted in countries like Thailand, Taiwan, South Africa, China, Australia, Turkey, Iran and USA $[9,12,13,19]$. Those studies were done mainly in the manufacturing sector in which the sector is one of the significant contributors for the economy of a country, apart from agriculture and service sectors [20]. In Malaysia, the manufacturing sector remains as the main driver for the growth of its economy, other than the service sector (Economic Report 2017/18, 2018) [21]. In addition, it was strongly suggested to conduct the study in other countries apart from the countries mentioned above, in order to see a more comprehensive pattern of the user acceptance factors and further study on them [12, 19, 22].

\section{UNDERLYING THEORIES}

\subsection{The UTAUT Model}

UTAUT was developed by Venkatesh et el. (2003) [23] and has been the most outperformed individual models among the other models like Technology Acceptance Model (TAM) and Theory of Reasoned Action (TRA) by Davis et al. (1989) [24], and few other individual models. It is able to explain $70 \%$ of variance in intention of using Information System (IS) while incorporating dynamic individual aspects in theoretical perspectives. The effects of individual and social factors were well studied in this theory. Figure 1 depicts the UTAUT model.

\subsection{IS Continuance Model}

Based on Expectation Confirmation Theory (ECT) by Oliver (1980) [24], a more refined theory was conceptualized by Battacherjee (2001) [25]. While ECT was tested in marketing domain, which was designed in justifying repurchasing intention of customers, the IS Continuance Model (ISCM) identifies the 
determinants for continuance intention in IS domain. Two important determinants that served as the contribution for this model are confirmation and satisfaction. They have been used in a lot of studies related to IS continuous usage. Therefore, the research problem for this study is to investigate and explore the determinants that have an influence towards the continuous usage of BI, in Malaysian manufacturing sector. ISCM Model (Bhattacherjee, 2001) as shown in Figure 2.

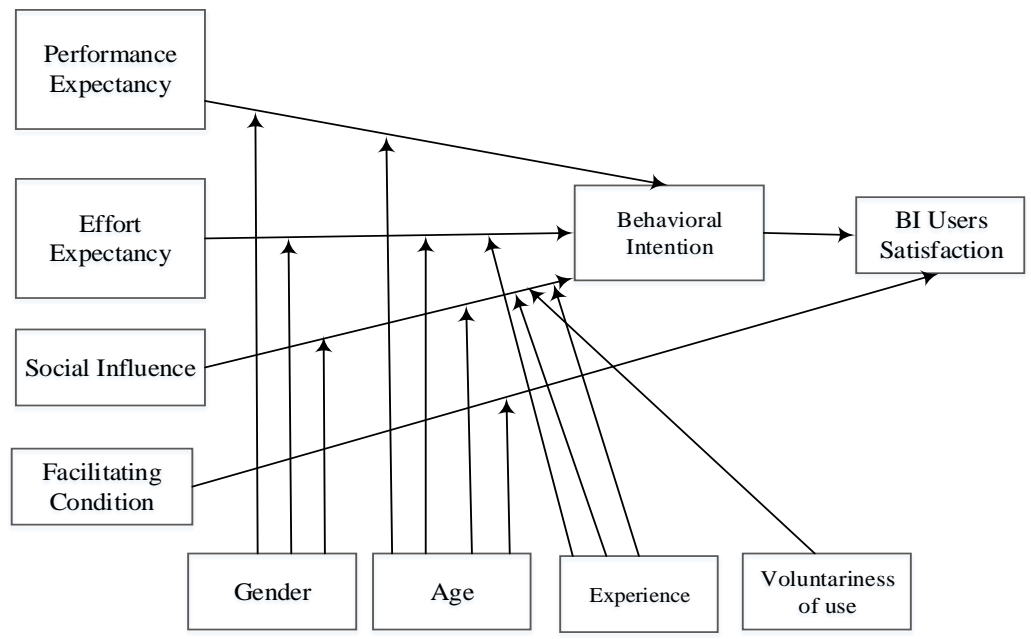

Figure 1. UTAUT Model (Venkatesh et al., 2003)

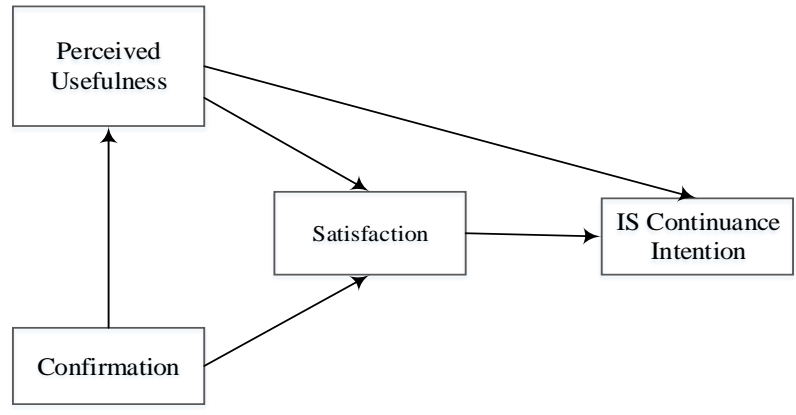

Figure 2. ISCM Model (Bhattacherjee, 2001)

\section{THE RESEARCH MODEL}

This research proposes the construction of a model upon two mature theoretical models as shown in Figure 3. The model is built assuming continuous usage of BI is influenced by individual-related determinants of users.

Based on the review of the literatures in section 3, the factors that influence the continuous usage of $\mathrm{BI}$ in manufacturing are performance expectancy, effort expectancy, social influence, facilitating condition, confirmation, and users' satisfaction. Performance expectancy, effort expectancy, social influence and facilitating condition are moderated by other variables such as gender, age, experience and voluntariness of use. In UTAUT, Venkatesh et al. (2003) [23] identified the moderating variables to moderate the effect of the four main variables in UTAUT. Therefore, the factors identified derived 20 hypotheses as follows [23-26]:

Main hypotheses:

H1: There is a significant influence between performance expectancy and confirmation to use BI.

$\mathrm{H} 2$ : There is a significant influence between effort expectancy and confirmation to use BI.

H3: There is a significant influence between social influence and confirmation to use BI.

$\mathrm{H} 4 \mathrm{a}$ : There is no significant influence between facilitating condition and confirmation to use BI.

$\mathrm{H} 4 \mathrm{~b}$ : There is a significant influence between facilitating condition and satisfaction in using BI.

H5: There is a significant influence between behavioral intention and satisfaction in using BI.

H6: There is a significant influence between satisfaction of user with BI use and continuous use of BI.

A model of determinants for continuous usage of business intelligence in... (Ernie Mazuin Mohd Yusof) 
H7: There is a significant influence between performance expectancy and satisfaction in using BI.

H8: There is a significant influence between performance expectancy and continuous use of BI.

Moderator Effects Hypotheses:

H9a: Performance expectancy influences confirmation to use BI systems stronger for men than for women.

H10a: Effort expectancy influences confirmation to use BI stronger for women than for men.

H11a: Social influence influences confirmation to use BI stronger for women than for men.

H9b: Performance expectancy influences confirmation to use BI systems stronger for young users than for old users.

H10b: Effort expectancy influences confirmation to use BI stronger for old users than for young users.

H11b: Social influence influences confirmation to use BI stronger for old users than for young users.

H12a: Facilitating condition influences satisfaction to use BI stronger for old users than for young users.

H10c: Effort expectancy influences confirmation to use BI stronger for inexperienced users than forexperienced users.

H11c: Social influence influences confirmation to use BI stronger for inexperienced users than forexperienced users.

H12b: Facilitating condition influences satisfaction to use BI stronger for experienced users than forinexperienced users.

H11d: Social influence influences confirmation to use BI stronger in compulsory circumstance than involuntarily circumstance.

The performance expectancy and effort expectancy factors that are shared between the two models will provide more explanatory power in explaining the BI continuous usage [27]. Furthermore, integrating other predictors from the two models contributes to a better understanding of continuous usage of BI rather than from each model on its own.

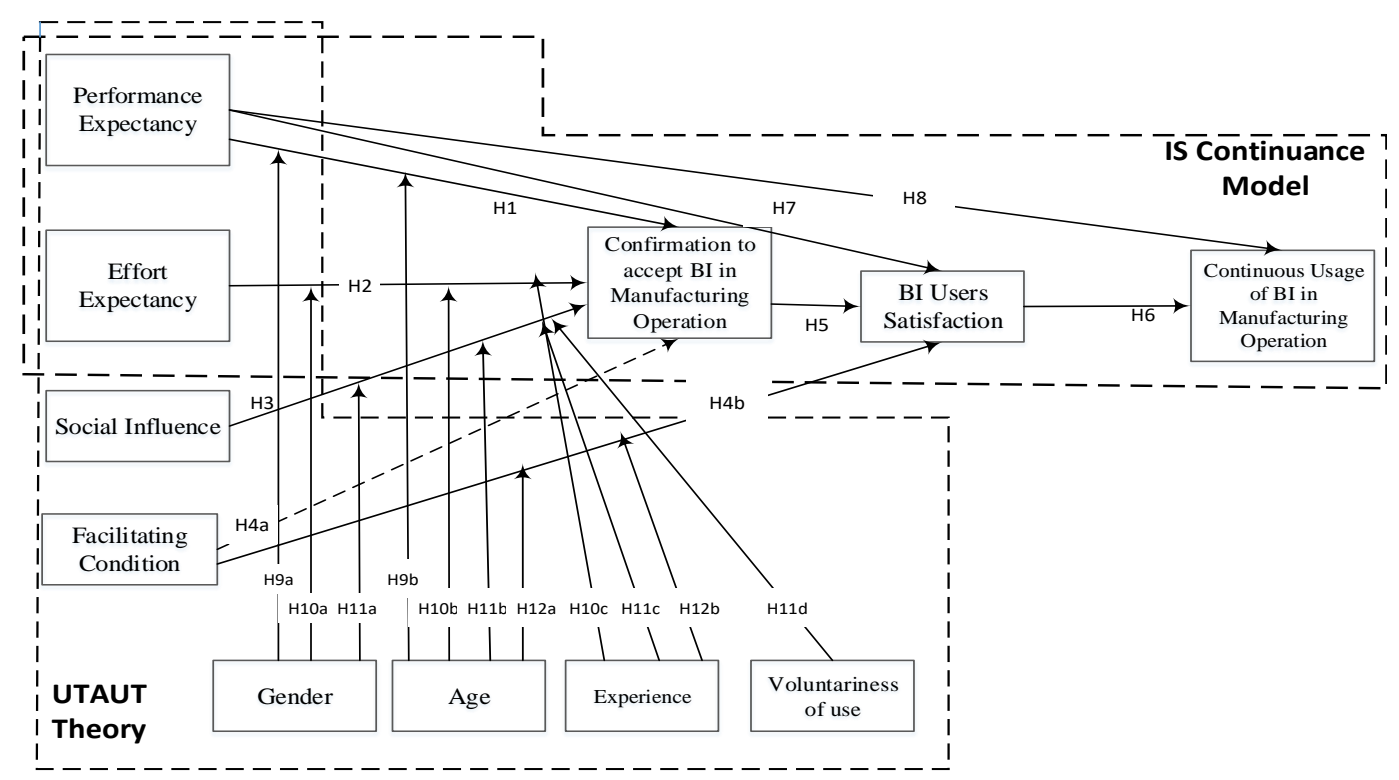

Figure 3. The research conceptual model

\section{THE METHODOLOGY}

A quantitative data analysis approach will be used to interpret responses gathered from the Malaysian manufacturing organizations, through survey questionnaires instruments. To ensure the validity of the instruments and research model, they will be sent to expert evaluators for further scrutiny. Comments from the evaluators will be considered in the process of correcting and modification of the instruments as well as the developed research model. The output of this process are the finalized questionnaires and model.

The questionnaires will be distributed to the employees of manufacturing organizations exist in Malaysia. The targeted sample size for the data is between 100 to 150 respondents. This is in line with Hsu et al. (2009) [28] whom in his empirical findings stated that the suitable approximation of the sampling is between 100 to 150 respondents. Then, the data will be analyzed and validated using Structural Equation Modelling (SEM) to investigate the causal and mediating relationships between the determinants. This 
research employs two steps of data analysis process for the SEM to produce an accurate measurement and structural model, as explained in section 5.2.

\subsection{Survey Questionnaire}

The questionnaire design will be based on the theoretical models involved that include demographic information and the BI use of the respondents in the first section [29]. The second section in the questionnaires will incorporate a list of questions that are related to the constructs of the research conceptual model. 5-point Likert scales will be used for measuring the constructs, ranging from 1 (strongly disagree) until 5 (strongly agree).

\subsection{Data Analysis}

There are two stages of data analysis under this phase. At the first stage, data screening will be performed using IBM Statistic Version 21. This stage is important since before doing any statistical analysis, the reliability of the data must be carried out first. Examples of the discrepancies in the data that must be screened are missing data and outliers in the data [30]. The assessment of normality of the data will also be performed here.

The second stage concerns on the assessment of inner and outer research models using Structural Equation Modeling (SEM) through IBM SPSS AMOS Version 23. In this stage, values for the convergent and discriminant validity between the constructs in the model will be determined. For convergent validity, constructs measurement will be done. The acceptable value for factor loading is 0.50 or higher. Whereas for discriminant validity, a more detailed processes will be done on the constructs. The variables' correlation index (must be less than 0.80) [31], AVE value (must be equal to or greater than 0.5) and square root of AVE will be determined here.

\section{EXPECTED RESULTS}

Upon the formulation of the research model, constructs and hypothesis, the collected data must be tested out. The tests will cover the reliability and validity aspects for confirming on the accuracy as well as consistency of the constructs and instruments. The results of the test is expected to portray the significant relationship between the individual related factors and the continuous usage of BI in Malaysian manufacturing organization. The causal relationships between these results will be expected to emerge as well. Eventually, the result is also hoping to provide a strong justification on the integration of UTAUT and ISCM that formulated on the emergence of the determinants on the continuous usage of BI in Malaysian manufacturing industry.

\section{DISCUSSION/CONCLUSION}

The gap exists concerning the scarcity of studies related to the factors that influence the continuous use of BI system in manufacturing, with consideration of relevant individual characters has been the driving force for this research to embark. Therefore, a new research conceptual model that integrates the UTAUT and ISCM is established. This new model will show individual-related determinants of BI that leads to the continuous usage of the system in Malaysian manufacturing organizations. A quantitative method with questionnaire as the instrument will be carried out in the field with relevant details assimilated in the questionnaire. Upon the data collection, the data will be screened and tested as in section 5.2 Data Analysis. The data analysis result will suggest individual-related determinants of BI continuous usage that contributes towards the improvement of manufacturing business processes and performance. Another potential aspect that can be considered to include in this study in the future is the level of satisfaction among the BI users in manufacturing. This is because users' satisfaction of a particular computer system will ensure the effective usage of the system that eventually will lead to a successful business performance [32]. This study enriched the previous academic researches on BI system implementation through developing a more comprehensive model for continuous usage of BI, catering a contribution to knowledge. From manufacturers stand point, this research contributes to improved business performance where considerations in implementing BI will be aided via this research model.

\section{REFERENCES}

[1] Yew Jie, L., Wong, D. H.-T., Mat Zain, Z., Amir Sjarif, N. N., Ibrahim, R., and Maarop, N. (2018). "Metrics and Benchmarks for Empirical and Comprehension Focused Visualization Research in the Sales Domain", Indonesian Journal of Electrical Engineering and Computer Science (IJEECS), 12(3), 1340-1348. https://doi.org/10.11591/ijeecs.v12.i3.pp1340-1348. 
[2] Williams, S. and Williams, N. (2004), “Assessing BI Readiness: The Key to BI ROI”, Business Intelligence Journal, 9(3), pp. 1-11.

[3] Williams, S. and Williams, N. (2010) "The Profit Impact of Business Intelligence". San Francisco: Morgan Kauffman.

[4] Hejazi, A., Abdolvand, N. and Harandi, S. R. (2016), "Assessing the Organizational Readiness for Implementing BI Systems", International Journal of Information Technology Convergence and Services (IJITCS), 6(1). doi: 10.5121/ijitcs.2016.6102.

[5] Olszak, C.M. and Ziemba, E. (2012) "Critical Success Factors for Implementing Business Intelligence Systems in Small and Medium Enterprises on the Example of Upper Silesia, Poland", Interdisciplinary Journal of Information, Knowledge and Management, 7, pp. 129-151.

[6] Sangar, A. B. (2014), "Measurement Metrics for Measuring Success of Business Intelligence System". PhD Thesis, Universiti Teknologi Malaysia, Johor, Malaysia.13. Gumpu, H. and Bach, C. (2015) 'The Perceived Impact Of Business Intelligence Tools On Marketing Success', Journal of Multidisciplinary Engineering Science and Technology, 2(12), pp. 3451-3456.

[7] Denic, N., Vujovic, V., Filic, S. and Spasic, B. (2016), "Analysis Of Key Success Factors For Business Intelligence Systems", Fascicle of Management and Technological Engineering, (2), pp. 73-76.

[8] Yoon, T. E., Ghosh, B. and Jeong, B. (2014), "User Acceptance of Business Intelligence (BI) Application: Technology, Individual Difference, Social Influence, and Situational Constraints", in Hawaii International Conference on System Science, pp. 3758-3766. doi: 10.1109/HICSS.2014.467.

[9] Sparks, B. H. and Mccann, J. T. (2015) "Factors influencing business intelligence system use in decision making and organisational performance", Int. J. Sustainable Strategic Management, 5(1), pp. 31-54.

[10] Ugur, N. G. and Turan, A. H. (2018), "Strategies For Bi Acceptance: Challenges And Solutions", in PressAcademia Procedia, pp. 237-240. doi: 10.17261/Pressacademia.2018.888.

[11] Kumar, V., Loonam, J., Allen, J. P. and Sawyer, S. (2016) "digital age", 31, pp. 97-100. doi: 10.1057/jit.2016.13.24.

[12] Hou, C. K. (2014), "User Acceptance of Business Intelligence Systems In Taiwan's Electronics Industry", Social Behavior and Personality, 42(4), pp. 583-596.

[13] Shiau, Y. C. P. H. W. (2014), "An empirical study of managersusage intention in BI", (5), pp. 247-258. doi: 10.1007/s10111-013-0261-z.

[14] Sönmez, F. (2018), “Technology Acceptance of Business Intelligence and Customer Relationship Management Systems within Institutions Operating in Capital Markets Technology Acceptance of Business Intelligence and Customer Relationship Management Systems within Institutions Op", International Journal of Academic Research in Business and Social Sciences, 8(2), pp. 400-422.

[15] Hou, W. and Gao, S. (2018), “An Investigation of the Managerial Use of Mobile Business Intelligence”, 10(3). doi: 10.17705/1PAIS.10304.

[16] Hatta, N. N. M., Miskon, S., Ali, N. M., Abdullah, N. S., Ahmad, N., Hashim, H., Alias, R. A. and Maarof, M. A. (2015) "Business intelligence system adoption theories in SMES : A literature review".

[17] Abai, N. H. Z., Yahaya, J. and Deraman, A. (2016), "Business Intelligence and Analytics in Managing Organizational Performance: The Requirement Analysis Model”, Journal of Advances in Information Technology V, 7(3). 208-213.

[18] Hatta, N. N. M., Abdullah, N. S. and Miskon, S. (2017), "Business Intelligence System Adoption Model for SMEs", Pacific Asia Conference on Information Systems (PACIS) Information Systems (PACIS), p. 15.

[19] Boonsiritomachai, W., Mcgrath, G. M. and Burgess, S. (2016), "Exploring business intelligence and its depth of maturity in Thai SMEs", Cogent Business \& Management. Cogent, 53, pp. 1-17. doi: 10.1080/23311975.2016.1220663.

[20] Azer, I., Hamzah, H. C., Mohamad, S. A. and Abdullah, H. (2016), "Contribution of Economic Sectors to Malaysian GDP”, in Regional Conference on Science, Technology and Social Sciences (RCSTSS 2014). doi: 10.1007/978-981-10-1458-1.

[21] Economic Report 2017/18. (2018). "Ministry of Finance Malaysia”. Putrajaya.

[22] Popovič, A., Puklavec, B., \& Oliveira, T. (2018), "Justifying business intelligence systems adoption in SMEs". http://doi.org/10.1108/IMDS-02-2018-0085

[23] Venkatesh, V., Morris, M. G., Davis, G. B. and Davis, F. D. (2003), "User Acceptance of Information Technology: Toward a Unified View", MIS Quarterly, 27(3), pp. 425-478.

[24] Davis, F. D., Bagozzi, R. P. and Warshaw, P. R. (1989), "User Acceptance of Computer Technology: A Comparison of Two Theoretical Models", Management Science, 35(8).

[25] Oliver, R. L. (1980). "A Cognitive Model of the Antecedents and Consequences of Satisfaction Decisions". Journal of Marketing Research, 17(4), 460-469.

[26] Bhattacherjee, A. (2001). "Understanding Information Systems Continuance: An Expectation-Confirmation Model". MIS Quarterly, 25(3), 351-370.

[27] Venkatesh, V., Thong, J. Y. L., Chan, F. K. Y., Hu, P. J.-H., and Brown, S. A. (2011). "Extending the two-stage information systems continuance model: incorporating UTAUT predictors and the role of context". Info Systems Journal, 21, pp. 527-555. https://doi.org/10.1111/j.1365-2575.2011.00373.x.

[28] Hsu, M.K., Wang, S.W. and Chiu, K.K. (2009). "Computer attitude, statistics anxiety and self-efficacy on statistical software adoption behaviour: an empirical study of online MBA learners". Computers in Human Behaviour. 25 (2), pp. 412-420. 
[29] N. Karthik, A.K. Parvathy, R. A. (2017). "Physicians' and Users Perceptions Towards Wearable Health Devices". Indonesian Journal of Electrical Engineering and Computer Science (IJEECS), 5(1), 234-242. https://doi.org/10.11591/ijeecs.v5.i1.pp.

[30] Rahman, N. S. A. (2017). "A Model Of Behaviour Intention Factors On Social Media Use For Collaborative Learning Affecting Teaching And Learning". PhD Thesis, Universiti Teknologi Malaysia, Skudai, Malaysia.

[31] Hair, J. F., Black, W. C., Basin, B. J., and Anderson, R. E. (2010). "Multivariate data Analysis". (7th ed). New Jersey: Upper Saddle River, Pearson Prentice Hall.

[32] B., Z., H., F. Z., and R., S. N. M. (2018), "Satisfaction Level of Mobile Application Implementation Towards Passengers: an Analysis". International Journal of Engineering \& Technology, 7(2.29), pp. 1102-1106. https://doi.org/10.14419/ijet.v7i2.29.14321

\section{BIOGRAPHIES OF AUTHORS}
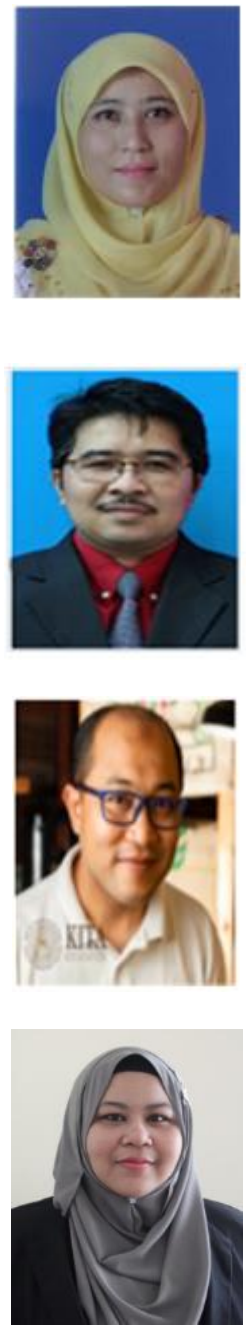

Ernie Mazuin Mohd Yusof received her B.Eng. in Computer and Information Systems Engineering from the International Islamic University Malaysia (IIUM) in 1999. She earned MSc in Computer Science from the Universiti Teknologi Malaysia (UTM). She is currently pursuing her Doctor Philosophy in UTM. She was holding a Senior Engineer post in electronics manufacturing company. She is currently a lecturer in Instrumentation \& Control Engineering section, Universiti Kuala Lumpur, Malaysian Institute of Industrial Technology (UniKL MITEC). Her research interests cover business intelligence, manufacturing data visualization, Supply Chain Management and Internet of Thing (IoT). Her current project is business intelligence implementation in manufacturing.

Mohd Shahizan Othman received his B.Sc in Computer Science with a major in Information Systems from Universiti Teknologi Malaysia (UTM), Malaysia, in 1998. Then he earned Msc in Information Technology from the Universiti Kebangsaan Malaysia (UKM), Malaysia. Soon after, he graduated for his $\mathrm{PhD}$ in Web Information Extraction, Information Retrieval and Machine Learning from UKM. He is currently an Associate Professor at the School of Computing, Faculty Engineering, UTM. His research interests are in information extraction and information retrieval on the web, web data mining, content management, machine learning, social learning, e-learning, business intelligence, and geographic information system (GIS).

Ahmad Rizal Mohd Yusof received his B.IT in Industrial Computing from Universiti Kebangsaan Malaysia (UKM), in 2000. Then he received M.IT in Computer Science from the UKM in 2003. He received his PhD in Knowledge Management from UKM in 2009. He is currently a senior lecturer at the Institute of Ethnic Studies (KITA), UKM. His research interests are in the Knowledge Management and Database Development, focusing on the Malay world and Malaysian Studies.

Zirawani Baharum received her B.Sc in Computer Science and Information System from Universiti Teknologi Malaysia (UTM), in 2003. Then she received MSc in Information Technology from UTM in 2004. She received her PhD in Computer Science from UTM in 2017. She is currently a senior lecturer in Technical Foundation section, Universiti Kuala Lumpur, Malaysian Institute of Industrial Technology (UniKL MITEC). Her research interests are in the computer modelling and simulation, computer science and Information and Communication Technology (ICT). 